\title{
A Psicologia como o Estudo de Interações ${ }^{1}$
}

\author{
João Claudio Todorov² \\ Universidade de Brasília
}

\begin{abstract}
RESUMO - O artigo analisa os problemas existentes em variedades de definições de Psicologia e expõe as vantagens, do ponto de vista da Análise do Comportamento, de definir-se Psicologia como o estudo de interações organismo-ambiente. As interações organismo-ambiente são tais que podem ser vistas como um continuum em que a passagem da Psicologia para a Biologia ou para as Ciências Sociais é muitas vezes uma questão de convencionar-se limites. A análise experimental do comportamento utiliza-se de contingências e de relações funcionais como instrumentos para o estudo de interações organismo-ambiente.
\end{abstract}

Palavras-chave: definição de Psicologia; análise do comportamento; interações; áreas da Psicologia.

\section{Psychology as the Study of Interactions}

\begin{abstract}
The problems with the variety of definitions of Psychology are analyzed, and the advantages from the point of view of Behavior Analysis, on defining Psychology as the study of organism-environment relations. Such interactions can be seen as a continuum where the passage from Psychology to Biology or to Social Sciences is often a matter of convenience. The experimental analysis of behavior uses contingencies and functional relationships as tools for the study of organismenvironment relations.
\end{abstract}

Key words: definition of Psychology; behavior analysis; interactions; subdivisions of Psychology.

There is no way to define the subject matter of psychology so that the definition will please all psychologists. Any definition turns out either too exclusive to be useful or too general to be meaningful. Yet some approximate may be sketched in.

(Marx \& Hillix, 1963, p. 31)

Definições de Psicologia têm variado no tempo e de acordo com as características de seus autores. Problemas surgidos no âmbito da Filosofia ou da ciência refletem-se em várias dessas definições. Por exemplo, é muito conhecida a definição de Psicologia como o estudo da mente. Entre outros problemas, essa definição coloca a questão de saber-se o que é a mente para que a definição seja inteligível. Alguns preferem referir-se a uma vida mental, um conceito aparentemente menos estático do que mente. A Psicologia seria a ciência da vida mental, o que quer que venha a ser vida mental. Outros, mais preocupados com o significado e as implicações dos termos incluídos em uma definição, afirmam ser a Psicologia o estudo do comportamento. Essa definição, como as anteriores, antes de explicar algo, levanta a necessidade de outra definição; neste caso, a definição de comportamento.

1 Reedição de texto publicado em 1989, no volume 5 número 3, na revista Psicologia: Teoria e Pesquisa (pp. 347-356).

$\mathrm{O}$ autor agradece as sugestões feitas por três autores anônimos.

2 Endereço: Departamento de Processos Psicológicos Básicos, Instituto de Psicologia, Universidade de Brasília, Brasília, DF. 70910.
Indiferentes às deficiências das definições mencionadas, há os que se preocupam com uma definição que contente a mentalistas e a comportamentalistas. Para estes, a Psicologia seria o estudo do comportamento e da vida mental. Contudo, a reunião em uma mesma frase de dois termos indefinidos não melhora uma definição. Em lugar de colocar um problema de cada vez, e contentar a pelo menos uma das partes, essa definição descontenta a um só tempo mentalistas e comportamentalistas.

Preferimos, portanto, caracterizar a Psicologia desde um ponto de vista e tentar, depois, mostrar como essa caracterização é compatível com os variados tipos de atividades do psicólogo na atualidade dos anos 1980. Não afirmamos que seja possível ou desejável uma tradução simples das várias linguagens e teorias correntes; estamos afirmando que este trabalho é uma tentativa de caracterizar a Psicologia a partir do ponto de vista de uma análise do comportamento e de mostrar como o que se faz na área de Psicologia é compatível com essa caracterização.

\section{Comportamento e Interação}

Science, and psychology as part of it studies relationship. What, then, does psychology study in relation to responses? The answer seems to be: nearly every thing that can be related.

(Marx \& Hillix, 1963, p. 32).

A Psicologia estuda interações de organismos, vistos como um todo, com seu meio ambiente (Harzem \& Miles, 1978). Obviamente não está interessada em todos os tipos 
possíveis de interações nem em quaisquer espécies de organismos. A Psicologia se ocupa fundamentalmente do homem, ainda que para entendê-lo, muitas vezes, tenha que recorrer ao estudo do comportamento de outras espécies animais (Keller \& Schoenfeld, 1950). Quanto às interações, estão fora do âmbito exclusivo da Psicologia aquelas que se referem a partes do organismo e são estudadas pela Biologia, e as que envolvem grupos de indivíduos tomados como unidade, como nas Ciências Sociais. Claro está que a identificação da Psicologia como distinta da Biologia e das Ciências Sociais não se baseia em fronteiras rígidas: as áreas de sobreposição de interesses têm sido importantes a ponto de originar as denominações de Psicofisiologia e Psicologia Social, por exemplo. As interações organismo-ambiente são tais que podem ser vistas como um continuum no qual a passagem da Psicologia para a Biologia ou para as ciências sociais é muitas vezes questão de convencionar-se limites ou de não se preocupar muito com eles.

Nessa caracterização da Psicologia, o homem é visto como parte da natureza. Nem pairando acima do reino animal, como viram pensadores pré-darwinianos, nem mero robô, apenas vítima das pressões do ambiente, na interpretação errônea feita por alguns autores de um comportamentalismo inexistente. Os homens agem sobre o mundo, modificam-no e, por sua vez, são modificados pelas conseqüências de sua ação. Alguns processos que o organismo humano compartilha com outras espécies alteram o comportamento para que ele obtenha um intercâmbio mais útil e mais seguro em determinado meio ambiente. Uma vez, estabelecido um comportamento apropriado, suas consequiências agem por meio de processo semelhante para permanecerem ativas. $\mathrm{Se}$, por acaso, o meio se modifica, formas antigas de comportamento desaparecem enquanto novas conseqüências produzem novas formas.

Essa visão da natureza humana nem é nova nem é exclusiva da Psicologia ou do comportamentalismo. O que torna a moderna análise do comportamento distinta é seu uso e a exploração das possibilidades que a visão oferece para o estudo de interações organismo-ambiente.

\section{Níveis de Interações Organismo-Ambiente}

As interações organismo-ambiente têm, historicamente, caracterizado áreas da Psicologia, dependendo de quais subclasses de interações são consideradas. Ainda que uma divisão do meio ambiente em externo (o mundo-fora-dapele) e interno (o mundo-dentro-da-pele) seja artificial, pois não tem que haver necessariamente dicotomia, a Psicologia evoluiu até o presente com áreas mais ou menos independentes especializadas em interações principalmente envolvendo o meio ambiente externo (psicofísica, por exemplo) ou com ênfase exclusiva no meio ambiente interno (abordagens psicodinâmicas da personalidade, por exemplo). Tanto o ambiente externo quanto o interno tem sido também dicotomizados (Quadro 1). Quanto ao ambiente externo, há áreas da Psicologia especializadas no estudo de interações organismo-ambiente externo físico (ergonomia, por exemplo), outras voltadas para uma interação organismo-ambiente externo social (Psicologia Organizacional). Já o ambiente interno é visto como biológico em áreas como a Psicofisiologia ou histórico nas áreas que se ocupam de processos internos conceituais sem referência imediata a um substrato biológico.

Quadro 1. Níveis de interações organismo-ambiente.

INTERAÇÕES ORGANISMO-AMBIENTE

EXTERNO Físico
Social

INTERAÇÕES ORGANISMO-AMBIENTE

$\begin{array}{ll} & \text { Biológico } \\ \text { INTERNO } & \text { Histórico }\end{array}$

\section{Ambiente externo}

O comportamento altera o meio ambiente pelas ações mecânicas, e suas propriedades ou dimensões se relacionam freqüentemente, de uma forma simples, com os efeitos produzidos. Quando um homem caminha em direção a um objeto, ele se vê mais próximo deste; quando procura alcançá-lo, é provável que se siga um contacto físico; ele o segura, levanta, empurra ou puxa, o objeto costuma mudar de posição de acordo com as direções apropriadas. Tudo isso decorre de simples princípio geométrico e mecânico. Muitas vezes, porém, um homem age apenas indiretamente sobre o meio do qual emergem as consequiências últimas de seu comportamento. Seu primeiro efeito é sobre outros homens. Um homem sedento, por exemplo, em vez de dirigir-se a uma fonte, pode simplesmente pedir "um copo d'água", isso é, pode produzir um comportamento constituído por certo padrão sonoro, o qual, por sua vez, induz alguém a lhe dar um copo d'água. Os sons em si mesmos são facilmente descritíveis em termos físicos, mas o copo de água só chega ao falante como conseqüência de uma série complexa de acontecimento que incluem o comportamento de um ouvinte. A conseqüência última, o recebimento de água, não mantém qualquer relação geométrica ou mecânica com a forma do comportamento de "pedir água". Na verdade, é característico desse comportamento o fato de ele ser impotente contra o mundo físico. Raramente nossos gritos derrubam as muralhas de Jericó ou somos bem sucedidos em ordenar ao sol para que não se mova ou às ondas para que se acalmem. Palavras não quebram ossos. As consequiências de tal comportamento surgem por intermédio de uma série de acontecimentos não menos físicos ou inevitáveis que as ações mecânicas, mas bem mais difíceis de descrever. (Skinner, 1978, pp. 15-16).

O trecho citado ilustra a divisão do ambiente externo em físico e social. As interações do organismo com seu ambiente social não são de natureza diferente daquelas interações com seu ambiente físico; são apenas mais difíceis de descrever. Essa dificuldade, entretanto, parece ser responsável pelo desenvolvimento independente de diversas áreas da Psicologia e pelas tentativas de desenvolver-se diferentes conceitos e princípios. 


\section{Ambiente interno}

Nas interações organismo-ambiente sempre estão presentes interações com o ambiente interno, seja biológico, seja histórico, da mesma forma que estão presentes em interações sociais. Os quatro aspectos em que o ambiente está sendo examinado são indissociáveis. Dois organismos interagem situados no espaço e no tempo, e nessa interação são importantes processos biológicos internos a cada indivíduo, bem como as experiências passadas de cada um com outras interações sociais. No desenvolvimento da Psicologia, entretanto, também no caso do ambiente interno, as diversas áreas progrediram independentemente. Mais ainda que na distinção entre ambiente físico e social, as dificuldades de descrição do que ocorre no ambiente interno tornaram inevitável esse desenvolvimento independente.

\section{Ambiente interno biológico}

Não obstante todo o progresso da Biologia, as dificuldades encontradas atualmente pelos psicólogos interessados no substrato biológico das interações que estudam não são muito diferentes daquelas encontradas por Freud no final do século passado ou por Skinner nos anos 1930. Há progressos na área, no entanto (ver Lubinski \& Thompson, 1987; Razran, 1961). É possível afirmar-se que alterações internas do organismo participam das interações organismo-ambiente tanto como estímulos que controlam respostas que os antecedem ou os seguem, quanto como respostas controladas pelos estímulos componentes da interação, como veremos mais adiante.

\section{Ambiente interno histórico}

Em todas as orientações teóricas da Psicologia, a história passada de interações organismo-ambiente tem um papel considerável na explicação de interações presentes. Seja pelo conceito de traço dos psicólogos gestaltistas, seja por meio do conceito de história passada de reforçamento dos comportamentalistas, presume-se que o organismo age agora não apenas em função de ambiente externo presente. É muitas vezes apenas tácita, outras explícita, a pressuposição de que o organismo transporta consigo os resultados de interações passadas. Nessas condições, dois tipos de teorias surgem, ambas referindo-se a eventos na história passada do organismo, sem referência à maneira como essa história é transportada. Ou discorrem sobre um aparato mental, apenas conceitual, como nas várias versões atuais da psicanálise ou referem-se a contingências passadas, observadas ou hipotéticas, como nas também variadas versões atuais do comportamentalismo. Lacan (1979), discutindo Bergmann, textualmente diz:

No artigo de Bergmann, "Germinal Cell", o que é dado como a célula germinal da observação analítica, é a noção de reencontro e de restituição do passado. Ele se refere aos Studien uber Hysterie para mostrar que Freud, até o fim de suas obras, até as últimas expressões do seu pensamento, mantém sempre no primeiro plano essa noção do passado, sob mil formas, $e$ sobretudo sob a forma de reconstrução. (Lacan, 1979, p. 36).

\section{Indissociabilidade dos vários níveis de interações} organismo-ambiente

Um vago senso de ordem emerge de qualquer observação demorada do comportamento humano. Qualquer suposição plausível sobre o que dirá um amigo em dada circunstância é uma previsão baseada nessa uniformidade. Se não se pudesse descobrir uma ordem razoável, raramente poder-se-ia conseguir eficácia no trato com os assuntos humanos. Os métodos da ciência destinam-se a esclarecer essas uniformidades e torná-las explícitas. As técnicas do trabalho de campo do antropólogo e do psicólogo social, os procedimentos da clínica psicológica e os métodos experimentais rigorosos de laboratório estão todos dirigidos para esse final, assim como os instrumentos matemáticos $e$ lógicos da ciência. (Skinner, 1967, p. 28).

Comportamento e ambiente são termos difíceis de manejar, pois têm significados demasiado amplos. Assim que tentamos utilizá-los, nos deparamos formulando as questões: Que tipo de comportamento? Que aspecto de ambiente? Essa é outra maneira de afirmar que sempre que tentamos descrever o comportamento ou o ambiente de um organismo somos forçados a decompô-lo em partes. A análise é essencial para a descrição em nossa ciência tanto quanto em outras. (Keller \& Schoenfeld, 1950, p. 2).

A decomposição do conceito de ambiente em externo, físico ou social, e interno, biológico ou histórico, é apenas um recurso de análise útil para entender-se a fragmentação da Psicologia em diversos campos e para apontar os diversos fatores que, indissociáveis, participam das interações estudadas pelos psicólogos. Sem a decomposição necessária para a análise, o todo é ininteligível; por outro lado, a ênfase exclusiva nas partes pode levar a um conhecimento não-relacionado ao todo. O jogo constante de ir e vir, de atentar para a interrelação das partes na composição do todo é essencial para o entendimento das interações organismo-ambiente.

\section{Comportamento}

Assim como o ambiente pode ser analisado em diferentes níveis, o comportamento pode ser entendido em diferentes graus de complexidade. Não é a quantidade ou a qualidade de músculos ou glândulas envolvidas ou os movimentos executados o que importa. O comportamento não pode ser entendido isolado do contexto em que ocorre. Não há sentido em uma descrição de comportamento sem referência ao ambiente, como não há sentido, para a Psicologia, em uma descrição do ambiente apenas. A descrição "Maria correu" é inútil para a análise do comportamento; sem antecedentes e conseqüentes do evento descrito, nada se pode concluir do episódio. Os conceitos de comportamento e ambiente e de resposta e estímulo são interdependentes. Um não pode ser definido sem referência ao outro.

Quando nos lançamos a construir uma ciência do comportamento, somos imediatamente confrontados por dois problemas. 
O primeiro problema é de dizer quanto do que ocorre no mundo é considerado comportamento. Todas as mudanças em estado dos organismos são comportamentos ou apenas parte delas? E se apenas parte delas, então quais? (...) O segundo problema é o de selecionar unidades de comportamento. Como deve o comportamento ser dividido em unidades de maneira a tomar possível uma explicação?(...) Felizmente, não é necessário ser possível afirmar exatamente o que é comportamento antes de iniciarmos a construção de uma ciência do comportamento. Podemos isolar algumas instâncias do comportamento e começar por estudá-las, mesmo que não seja possivel definir exatamente o que é e o que não é comportamento. (Shick, 1971, p. 413).

Por meio de análise, os psicólogos chegam aos conceitos de estímulo e resposta. Um estímulo pode ser provisoriamente definido como "uma parte ou mudança de uma parte do ambiente", e uma resposta pode ser definida como "uma parte ou mudança em uma parte do comportamento". Devemos reconhecer, entretanto, que um estímulo não pode ser definido independentemente de uma resposta. (Keller \& Schoenfeld, 1950, p. 3).

\section{O Modelo de Staddon para o Estudo de Interações}

Devemos a Hume a noção atual dos conceitos de causa e efeito. A é causa do evento $\mathbf{B}$ se a sucessão $\mathbf{A}$ e $\mathbf{B}$ é invariável. No sentido corrente, causa é uma mudança em uma variável independente e efeito, uma mudança em uma variável dependente, e a relação de causa e efeito, uma relação funcional (Skinner, 1967). Em uma correlação, a sucessão invariável A B pode ser observada, e a distinção entre causa e correlação depende da experimentação. Somente pela manipulação da variável independente é possível afirmar-se algo a respeito de uma relação funcional. A mera observação de uma sucessão invariável pode perfeitamente referir-se apenas a uma correlação: A e B ocorrem juntos em virtude de uma variável independente, $\mathrm{C}$.

Note-se, entretanto, que uma causa é invariavelmente seguida por seu efeito apenas sob certas condições. A perda de um parente próximo, por exemplo, será seguida ou não de depressão dependendo de fatores como a idade de quem morreu, a idade do parente que sobrevive, o grau de parentesco, o grau de afetividade no relacionamento, a duração da enfermidade, a magnitude da herança, etc. No exemplo, a relação funcional perda de um parente próximo - depressão exógena depende de variáveis de contexto, que são os fatores apontados (Staddon, 1973). Staddon, em um artigo sobre a noção de causa em Psicologia, mostra como a noção de contexto não é limitada temporalmente. Contexto não se refere apenas a características atuais do ambiente externo. No nosso exemplo, o grau de afetividade pode ter se estabelecido há anos por meio de interações envolvendo os dois parentes e exerce sua influência mesmo que a morte ocorra num período em que os dois não se comunicam há muito tempo. O exemplo serve também para exemplificar a arbitrariedade na escolha do que é causa e do que é contexto. Poderíamos falar da relação funcional grau de parentesco-depressão, dado o contexto da morte de um parente próximo. A seleção de uma variável como causa e a designação de outras como contexto vai depender de quais são os interesses envolvidos no estudo, pois quando variáveis de contexto são consideradas, uma relação de causa e efeito é apenas um instrumento para a descoberta de princípios de maior generalidade. Princípios são a descrição mais econômica do conjunto de relações causais e variáveis de contexto que dão origem a eles. Um sistema de relações funcionais bem definidas resultará em uma teoria útil se também vier acompanhada de especificações de onde, no ambiente externo, as variáveis independentes e as variáveis de contexto devem ser encontradas, além de instruções sobre como detectá-las e/ou medi-las. Causas, pois, são os ingredientes primários e empíricos com os quais se constroem explicações (teorias) mais compreensivas. Portanto, o termo "causa" tem sentido apenas dentro de uma teoria ou modelo. Não há uma causa real de um dado evento. Há apenas modelos do mundo mais ou menos adequados, e sempre passíveis de modificação, de acordo com critérios como predição, simplicidade e generalidade, entre outros (Staddon, 1973).

\section{A Contingência como Instrumento para o Estudo de Interações}

$\mathrm{Na}$ análise do comportamento, o termo contingência é empregado para se referir a regras que especificam relações entre eventos ambientais ou entre comportamento e eventos ambientais (Schwartz \& Gamzu, 1977; Skinner, 1967; Weingarten \& Mechner, 1966). O enunciado de uma contingência é feito em forma de afirmações do tipo "se, então". A cláusula "se" pode especificar algum aspecto do comportamento (Weingarten \& Mechner, 1966) ou do ambiente (Schwartz \& Gamzu, 1977) e a cláusula "então" especifica o evento ambiental conseqüente. Assim como relações funcionais são instrumentos na busca de princípios mais gerais, contingências são utilizadas pelo psicólogo experimental na procura de relações funcionais. As contingências são as definições de variáveis independentes na análise experimental do comportamento. Weingarten e Mechner (1966) distinguem contingências enquanto definições de variáveis independentes, de proposições empíricas associadas às contingências.

Quando a cláusula "se" refere-se a algum aspecto do comportamento, como numa contingência do tipo "se ocorrer um aumento na produção, então o salário será aumentado", uma proposição empírica seria da forma "se um aumento na produção resultar em aumento no salário, a produção aumentará". A descrição da relação funcional entre aumentos da produção e aumentos no salário se completa com a indicação das variáveis de contexto, isso é, com a indicação das condições sob as quais a relação funcional será observada.

\section{Resumo e Conclusões}

A Psicologia estuda interações de organismos vistos como um todo, com seu meio ambiente. Ocupa-se fundamentalmente do homem, ainda que para entendê-lo muitas vezes tenha que recorrer ao estudo do comportamento de outras espécies animais. As interações organismo-ambiente são tais que podem ser vistas como um continuum no qual a 
passagem da Psicologia para a Biologia ou para as ciências sociais é muitas vezes questão de convencionar-se limites ou de não se preocupar com eles.

As interações organismo-ambiente têm, historicamente, caracterizado áreas da Psicologia, dependendo de quais subclasses de interações são consideradas. Há áreas da Psicologia especializadas em interações organismo-ambiente externo físico (ergonomia, por exemplo) e outras em interações com o ambiente externo social (Psicologia Organizacional, por exemplo).

A decomposição do conceito de ambiente em externo, físico ou social e interno, biológico ou histórico é apenas um recurso de análise útil para entender-se a fragmentação da Psicologia em diversos campos, e para apontar os diversos fatores que, indissociáveis, participam das interações estudadas pelo psicólogo. Apesar dos quatro aspectos terem gerado programas de pesquisa e de linguagens teóricas independentes, é possível sempre ver a Psicologia como análise de interações.

Pela análise de interações organismo-ambiente, os psicólogos chegaram aos conceitos de estímulo e resposta. Os conceitos de comportamento e ambiente, estímulo e resposta, são interdependentes. O comportamento não pode ser entendido isolado do contexto em que ocorre.

A análise experimental do comportamento utiliza-se de contingências e de relações funcionais como instrumentos para o estudo de interações organismo-ambiente. O experimentador manipula contingências em busca de relações funcionais e das condições (variáveis de contexto) nas quais podem ser observadas. Um sistema de relações funcionais constituirá uma teoria útil se vier acompanhado de especificações de onde e quando, no ambiente externo, as variáveis de contexto devem ser encontradas.

\section{Referências}

Harzem, P. \& Miles, T. R. (1978). Conceptual issues in operant psychology. Chichester: Wiley.

Keller, F. S. \& Schoenfeld, W. N. (1950). Principles of Psychology. New York: Appleton-Century-Crofts.

Lacan, J. (1979). O Seminário. Livro 1. Os escritos teóricos de Freud (versão brasileira de Betty Milan). Rio de Janeiro: Zahar.

Lubinski, D. \& Thompson, T. (1987). An animal model of the interpersonal communication of interoceptive (private) states. Journal of the Experimental Analysis of Behavior, 48, 1-15.

Marx, M. H. \& Hillix, W. A. (1963). Systems and theories in psychology. New York: McGraw-Hill.

Razran, G. (1961). The observable unconscious and the inferable conscious in current soviet psychophysiology: interoceptive conditioning, semantic conditioning, and the orienting reflex. Psychological Review, 68(2), 81-147.

Schick, K. (1971). Operants. Joumal of the Experimental Analysis of Behavior, 15, 413-423.

Shwartz, B. \& Gamzu, E. (1977). Pavlovian control of operant behavior. Em W. K. Honing \& J. E. R. Staddon (Orgs.), Handbook of operant behavior (pp. 53-97). Englewood Cliffs: Prentice-Hall.

Skinner, B. F. (1967). Ciência e comportamento humano. Brasília: Editora da Universidade de Brasília.

Skinner, B. F. (1978). O comportamento verbal. São Paulo: Editora Cultrix.

Staddon, J. E. R. (1973). On the notion of cause, with applications to behaviorism. Behaviorism, 1, 25-63.

Weigarten, J. \& Mechner, F. (1966). The contingency as an independent variable of social interaction. Em T. Verhave (Org.), The experimental analysis of behavior (pp. 447-459). New York: Appleton-Century-Crofts. 